\title{
Anticorrosion Properties of Tin Oxide Coatings for Carbonaceous Bipolar Plates of Proton Exchange Membrane Fuel Cells
}

Taro KINUMOTO*, Keita NAGANO, Yuji YAMAMOTO,

Tomoki TSUMURA and Masahiro TOYODA

Department of Applied Chemistry, Faculty of Engineering, Oita University, 700 Dannoharu, Oita 870-1192, Japan

*Corresponding author: Taro KINUMOTO

Tel. \& Fax: +81-97-554-7905

E-mail: kinumoto@oita-u.ac.jp 


\section{Abstract}

An anticorrosive surface treatment of a carbonaceous bipolar plate used in proton exchange membrane fuel cells (PEMFCs) was demonstrated by addition of a tin oxide surface coating by liquid phase deposition (LPD), and its effectiveness toward corrosion prevention was determined. The tin oxide coating was deposited by immersion in tin fluoride and boric acid solutions, without any observable decrease in the bipolar plate electrical conductivity. Anticorrosion properties of a flat carbonaceous bipolar plate were investigated in an aqueous $\mathrm{HClO}_{4}$ electrolyte solution $\left(10 \mu \mathrm{mol} \mathrm{dm} \mathrm{dm}^{-3}\right)$ at $80{ }^{\circ} \mathrm{C} . \mathrm{CO}_{2}$ release due to corrosion was significant for the bare specimen above $1.3 \mathrm{~V}$, whereas no $\mathrm{CO}_{2}$ release was noted for the tin-oxide-coated specimen, even approaching 1.5 V. Moreover, minimal changes in contact angle against a water droplet before and after treatment indicated suppressed corrosion of the surface-coated specimen. Anticorrosion properties were also confirmed for a model bipolar plate having four gas flow channels. The tin oxide layer remained on the channel surfaces (inner walls, corners and intersections) after durability tests. Based on these results, tin-oxide-based surface coatings fabricated by LPD show promise as an anticorrosion technique for carbonaceous bipolar plates not only for PEMFCs but also for unitized regenerative fuel cells (URFCs).

\section{Keywords}

PEMFC, Carbonaceous bipolar plate, Durability, Tin oxide 


\section{Introduction}

Proton exchange membrane fuel cells (PEMFCs) are currently receiving considerable attention as power sources for stationary co-generation systems and for fuel cell vehicles (FCV). The carbonaceous bipolar plates found in PEMFCs are typically made from conductive carbon materials (graphite powders and carbon fibers), often in conjunction with several kinds of polymeric materials to enhance plate stability as well as workability in comparison to metallic analogs [1]. Previous studies on the electrochemical durability of carbonaceous composites used in the fabrication of bipolar plates were initially conducted by simulating the environment of the cathode of PEMFCs [2]. Specifically, electrochemical durability was previously investigated using an aqueous hydrochloric acid $\left(10 \mu \mathrm{mol} \mathrm{dm}{ }^{-3}\right)$ electrolyte solution under a nitrogen or oxygen atmosphere by means of a potential holding test from $0.8 \mathrm{~V}$ to $1.5 \mathrm{~V}$ against a reversible hydrogen electrode (RHE) at $80^{\circ} \mathrm{C} . \mathrm{CO}_{2}$ release, a phenomenon related to surface corrosion, was confirmed at holding potentials above $1.3 \mathrm{~V}$ using gas chromatography. In addition, contact angle measurements used to evaluate surface hydrophobicity, also indicative of corrosion processes, were also noticeably altered under the simulation conditions, even below $1.0 \mathrm{~V}$ (i.e., at the cathode potential of PEMFCs during operation) [2].

Despite the identification of carbonaceous bipolar plates as the most durable material among known candidates [1], its durability for long-term operation is not guaranteed [2]; thus, anticorrosion surface treatments are required. In this regard, coating plate surfaces with 
metal-based compounds such as noble metals, metal nitrides, metal carbides, or carbonaceous thin films are a typical approach for giving anticorrosion properties to metallic analogs [3-6]. Such coatings are attractive with regards to their anticorrosive properties; unfortunately, process costs are quite steep because of the high material cost of noble metals (e.g., gold) and application of gas phase reactions (vapor deposition, plasma polymerization, etc.), particularly. Since the costs of PEMFCs must ideally be low for commercialization, the costs of anticorrosion treatments should be as inexpensive as possible.

At present, tin oxide is considered an ideal candidate for anticorrosive coatings for carbonaceous components of PEMFC, because of its lower material cost in comparison to noble metals, higher durability, and electrical conductivity without any catalytic effects on carbon corrosion [7, 8]. And, tin oxide containing fluoride is also demonstrated by Wang and Turner for stainless steel bipolar plates [9]. Liquid phase deposition (LPD) is an efficient method for the successful preparation of various metal oxide particles as well as thin films by the decomposition of metal fluorides in an aqueous medium, accelerated by the addition of boric acid $[10,11]$. Compared to vapor deposition techniques, LPD offers lower capital equipment costs (based on aqueous precursors), and decreased processing temperatures, a preferable technique for reducing treatment costs [10]. Here, the cost for post treatment of boron and fluoride could be required for LPD. LPD also offers flexibility in the choice of substrates with respect to topography of the substrate; accordingly, LPD is an appropriate technique for a 
bipolar plate of considerable roughness with several gas channels [10]. Thereby, we attempted those to anticorrosive surface treatment of a carbonaceous bipolar plate. The desired metal oxide is generally obtained through LPD by the two chemical reactions as described below:

$$
\begin{aligned}
& \mathrm{MF}_{\mathrm{x}}^{(\mathrm{x}-2 \mathrm{n})^{-}}+\mathrm{nH}_{2} \mathrm{O} \leftrightarrows \mathrm{MO}_{\mathrm{n}}+\mathrm{xF}^{-}+2 \mathrm{nH}^{+} \\
& \mathrm{H}_{3} \mathrm{BO}_{3}+4 \mathrm{H}^{+}+4 \mathrm{~F}^{-} \leftrightarrows \mathrm{HBF}_{4}+3 \mathrm{H}_{2} \mathrm{O}
\end{aligned}
$$

Herein, we describe a coating method employing tin fluoride and boric acid to form a tin oxide coating layer on the carbonaceous bipolar plate. The LPD technique was used to conduct the anticorrosion treatment by application of a tin oxide layer on a carbonaceous bipolar plate. Efficacy of the tin oxide coating on corrosion prevention during exposure to the simulated environment of PEMFC operating conditions was firstly demonstrated by measuring $\mathrm{CO}_{2}$ release, a sign of corrosion. A model operational carbonaceous bipolar plate with four gas flow channels was also investigated.

\section{Experimental}

\subsection{LPD anticorrosion treatment of carbonaceous bipolar plates using tin oxide}

Commercially available flat carbonaceous bipolar plates $(50 \mathrm{~mm} \times 50 \mathrm{~mm}$; thickness: 2 $\mathrm{mm}$ ) without gas channels were employed as the test specimen. A plate of the same scale and 
composition having four gas flow channels 4 (width: $1 \mathrm{~mm}$; depth: $0.5 \mathrm{~mm}$ ) was also employed to investigate anticorrosion effects in explained latter. The average value of the in-plane electrical conductivity was measured as $c a .180 \mathrm{~S} \mathrm{~cm}^{-1}$, which satisfies the DOE target [12].

Deposition of a tin oxide coating on the carbonaceous bipolar plates was carried out by LPD. Tin fluoride ( $\mathrm{SnF}_{2}$; Aldrich: 334626$)$ and boric acid $\left(\mathrm{H}_{3} \mathrm{BO}_{3}\right.$; Kishida Kagaku: $\left.\mathrm{C} 32568 \mathrm{X}\right)$ were employed. $\mathrm{SnF}_{2}$ and $\mathrm{H}_{3} \mathrm{BO}_{3}$ solutions were prepared separately at the desired concentrations using highly pure water obtained from the Simplicity UV water purification system (MERCK Millipore). The aqueous solutions were mixed at the same volume in a plastic beaker. The reaction area boundary was enclosed by PTFE (polytetrafluoroethylene) tape, and the plates were then immersed for an arbitrary time under stationary conditions at room temperature. After the reaction, the surface was thoroughly washed with highly pure water. Finally, the plates were stored under atmospheric conditions for use in following experiments.

Electrical conductivity was measured by a four-probe method using a conductivity meter (Mitsubishi Chemical Analytech, Loresta GP). Surface morphology was observed by optical microscopy (OM; KEYENCE, VX-500F) and field-emission scanning electron microscopy (FE-SEM; JEOL, JSM-6701F), and was analyzed by energy dispersive X-ray spectrometry (EDS; JEOL, JED-2300) and Raman spectroscopy (LabRAM ARAMIS, Horiba Jobin Yvon). 


\subsection{Electrochemical durability tests}

Electrochemical durability was investigated using a potential holding test as described in a previous study [2]. The fabricated glass cell used in this study was the same composition as reported elsewhere $[2,7,13-15]$. The electrolyte employed was an aqueous $\mathrm{HClO}_{4}$ solution of

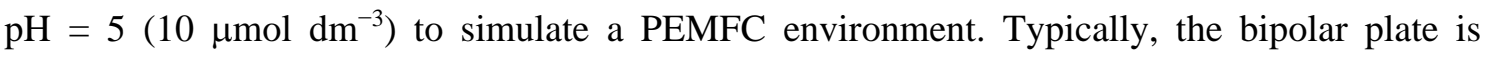
exposed to highly humidified gases and condensed water under ideal PEMFC operating conditions; unfortunately, this would bring the plate into contact with the somewhat acidic solution as used in this study due to electrolytic membrane decomposition under open circuit conditions, low (inadequate) humidity, and low load operating conditions [16]. Hence, the present experimental conditions could be regarded as a model environment experienced by the bipolar plates in PEMFCs. The counter electrode used was a gold mesh placed in a separate compartment. The reference electrode used was a $\mathrm{Ag} \mid \mathrm{AgCl}$ electrode connected to the cell by a Luggin capillary, and the potential was controlled using a reversible hydrogen electrode (RHE) scale. The bare and coated carbonaceous bipolar plates were only brought into contact with the electrolyte solution. Oxygen gas $(99.998 \%$, Japan Fine Products) was bubbled thoroughly through the electrolyte solution, and both gas inlets and outlets were sealed off by a rubber septum. Electrochemical durability tests were carried out using a potentiostat (Bio-logic, VMP3) from $0.8-1.5 \mathrm{~V}$ in a heating chamber controlled at $80{ }^{\circ} \mathrm{C}$. The potential was changed with a stepwise increase of $0.1 \mathrm{~V}$ every $24 \mathrm{~h}$. The following procedure was denoted "continuous 
test." After each test period, a defined amount of gas was collected from the cell via glass syringe. The amount of $\mathrm{CO}_{2}$ in the gas was quantified by gas chromatography (GC; Agilent, $6890 \mathrm{~N})$. The electrolyte was then replaced with a fresh solution for following test. Further durability tests (denoted "long-term tests") were also carried out at $0.1 \mathrm{~V}$ intervals between $0.6-1.0 \mathrm{~V}$ at $80{ }^{\circ} \mathrm{C}$ over $500 \mathrm{~h}$.

Hydrophobic properties of the test specimens were investigated by contact angle measurements against a water droplet with a contact angle meter (Kyowa Interfacial Science, Model CA-DT, and Excimer Inc., SImage mini). Contact angles $(\theta)$ were acquired at various locations on the specimen and an average value was obtained.

\section{Results and discussion}

\subsection{Anticorrosion treatment by tin oxide coating to carbonaceous bipolar plate}

Figure 1 shows a photograph and OM image of the test specimen after immersion in $\mathrm{SnF}_{2}$ and boric acid solutions $0.1 \mathrm{~mol} \mathrm{dm}^{-3}$ for $30 \mathrm{~h}$. As observed in Fig. 1(a), the color of the surface in contact with the solution was transformed from black (bare) to pale blue (after treatment), indicating that the experimental conditions are appropriate for anticorrosion tests. The boundary between the coating (lower) and bare (upper) area was clearly observed in the OM image, as shown in Fig. 1(b). A mosaic-like morphology was seen on the bare surface, suggesting that graphite particles tend to be present in a random orientation. Further, a "whitish" 
region could be observed in the lower area of the image, with no particles evident at this magnification, suggesting that the precipitate likely formed a thin film.

Figures 2(a) and (b) show FE-SEM images of the bare and coated carbonaceous bipolar plate surfaces, respectively. Flake-like graphite particles could be observed in Fig. 2(a), whereas surface morphology was dramatically changed after treatment, as seen in Fig. 2(b). Thus, LPD-mediated surface coating of the bipolar plate was successfully performed; unfortunately, the coating thickness could not be determined.

In order to investigate the elemental composition of the thin film precipitate, EDS analysis was carried out using a silicon detector equipped with FE-SEM; the obtained spectrum is shown in Fig. 3. As noted, peaks assignable to carbon, oxygen and tin were observed. The intense carbon signal was derived from the carbonaceous substrate, whereas the appearance of signals corresponding to oxygen and tin suggested these elements presence in the thin film. Next, the crystalline phase was investigated by Raman spectroscopy (spectrum not shown). A very broad peak assigned to the $\mathrm{A}_{1 \mathrm{~g}}$ vibration mode of $\mathrm{SnO}_{2}$ was noted at $c a .632 \mathrm{~cm}^{-1}$, in good agreement with the report by Sun et. al [17]. From these results, the coating layer was confirmed to be composed of a non-stoichiometric tin oxide thin film.

Sufficient electrical conductivity of PEMFC bipolar plates is a key requirement for higher cell performances. Electrical conductivity of the carbonaceous bipolar plate after treatment fell in the range of $180-190 \mathrm{~S} \mathrm{~cm}^{-1}$, closely matching that of the bare plate; these 
results indicate that bipolar plate conductivity was unchanged by the surface treatment with tin oxide. Accordingly, the method proposed in this study shows promise as an effective carbonaceous bipolar plate anticorrosion treatment.

\subsection{Electrochemical durability tests}

In the previously described study regarding the electrochemical durability of bare carbonaceous bipolar plates, the oxidation current was measured during the test and was gradually increased up to $1.2 \mathrm{~V}$, followed by a significant increase above $1.3 \mathrm{~V}$ [2]. Simultaneously, $\mathrm{CO}_{2}$ was detected by $\mathrm{GC}$, showing that the carbonaceous bipolar plate is subjected to corrosion above $1.3 \mathrm{~V}$ at $80{ }^{\circ} \mathrm{C}$ in the aqueous $\mathrm{HClO}_{4}$ solution as shown in Fig. 4 (square plots). This result is reasonable since the theoretical potentials for electrochemical oxidation of carbon to $\mathrm{CO}_{2}$ are rather noble than $1.3 \mathrm{~V}$ as denoted in Equation (3) [18]:

$$
\mathrm{C}+2 \mathrm{H}_{2} \mathrm{O} \leftrightarrows \mathrm{CO}_{2}+4 \mathrm{H}^{+}+4 \mathrm{e}^{-} \quad E_{0}=0.207 \mathrm{~V} v s . \mathrm{NHE}
$$

The potential for carbon oxidation to CO is given below [18]:

$$
\mathrm{C}+\mathrm{H}_{2} \mathrm{O} \leftrightarrows \mathrm{CO}+2 \mathrm{H}^{+}+2 \mathrm{e}^{-} \quad E_{0}=0.518 \mathrm{~V} v s . \mathrm{NHE}
$$


Figure 4 illustrates $\mathrm{CO}_{2}$ release from the tin oxide-coated carbonaceous bipolar plate as a function of time, where the upper horizontal axis and left vertical axis give the holding potential and $\mathrm{CO}_{2}$ release per surface area unit, respectively. $\mathrm{CO}_{2}$ release from the coated sample was not observed, even at elevated holding potentials approaching $1.5 \mathrm{~V}$, whereas $\mathrm{CO}_{2}$ release from the bare bipolar plate was apparent at potentials above $1.3 \mathrm{~V}$, as previously discussed [2]. This difference in $\mathrm{CO}_{2}$ release, and hence, corrosion, is obviously correlated to the presence of the tin oxide surface coating; in other words, a surface coating of tin oxide is effective against the corrosion of carbonaceous bipolar plates under the operating conditions of PEMFC.

Figures 5(a) and (b) show FE-SEM images of the bare and coated carbonaceous bipolar plate surfaces after continuous tests, respectively. As noted through comparison with the untreated bare sample (Fig. 2(a)), several cracks were produced on the surface of the bare specimen after the test (Fig. 5(a)), likely as the result of corrosion. In contrast, it is noteworthy that no significant change in surface morphology was observed for the coated specimen after being subjected a comparable high potential of $1.5 \mathrm{~V}$. It could be considered that a majority of the material remained from the FE-SEM image after the test (Fig. 5(b)). Although the chemical stability of tin oxide is demonstrably higher than that of carbon [10, 19-21], the possibility for tin oxide loss from the surface coating still remains.

Figure 6 shows the measured contact angles against a water droplet as a function of holding potential after long-term tests. The contact angle reflects the hydrophobicity (or 
hydrophilicity) of the bipolar plate; a change in contact angle is indicative of some change in surface properties, which can be correlated to corrosion of the surface [2, 14], as well as destabilization of cell performance in the present study. The contact angles for the bare and coated specimens were $95^{\circ}$ and $100^{\circ}$, respectively. The change in contact angle by tin oxide coating would be brought by changing the surface roughness. After long-term tests, the contact angles decreased with increasing holding potential, reaching $58^{\circ}$ at $1.0 \mathrm{~V}$ (decrease rate: $0.074^{\circ}$ $\mathrm{h}^{-1}$ ) for the bare specimen and $85^{\circ}\left(\right.$ decrease rate: $\left.0.03^{\circ} \mathrm{h}^{-1}\right)$ for the coated one. Thus, tin oxide surface coating deposition was shown to be a suitable strategy for maintaining long-term stable cell performance.

\subsection{Application for a model bipolar plate}

As discussed above, the anticorrosion effect of the tin oxide coating was confirmed by continuous and long-term durability tests. An actual operational bipolar plate has several gas flow channels; hence, it is of great importance to protect the whole of the surface including the channel inner walls, bottom, corners, and intersections. A model study was thus initiated to investigate these operative factors using a bipolar plate having four gas flow channels, as depicted in Fig. 7.

Figure 8 shows the amount of $\mathrm{CO}_{2}$ released from the carbonaceous plate coated with tin oxide during the continuous test. A very small current was observed on the order of several 
microamperes (chronoamperogram not shown). As shown in Fig. 8, it is worth noting that $\mathrm{CO}_{2}$ release was not observed during the durability test, indicating that the tin oxide coating applied by the LPD method is effective for suppressing corrosion of the carbonaceous bipolar plate. FE-SEM images of the bare and coated bipolar plates after the test are shown in Figs. 9(a) and (b), respectively. As observed in Fig. 9(b), the tin oxide coating remained intact on the entire surface of the coated specimen, even after the test.

The corrosion of bipolar plates induces severe deterioration of cell performance. The carbonaceous bipolar plate substrate employed in the present report was modified with a tin oxide surface coating using the LPD method, and subjected to corrosion at $1.3 \mathrm{~V}$; its durability was found to be markedly improved by the presence of this coating without any loss in electrical conductivity. Furthermore, this anticorrosion effect was maintained over $24 \mathrm{~h}$ at $1.5 \mathrm{~V}$ in a dilute perchloric acid solution $(\mathrm{pH}=5)$ at $80{ }^{\circ} \mathrm{C}$. It is unlikely that the potential of the bipolar plate surpassed the theoretical open circuit potential of PEMFCs under the normal operating conditions. Such a high potential situation is likely at the anode of URFCs (unitized regenerative fuel cells) $[3,22]$. In this regard, this study may also be of relevance to development of an effective anticorrosion technique for carbonaceous bipolar plates used in URFCs.

\section{Conclusion}


Anticorrosion treatment of a carbonaceous bipolar plate was performed by application of a tin oxide coating using the LPD technique, and its effectiveness was demonstrated. Deposition of a tin oxide coating on the carbonaceous bipolar plate was successfully carried out by immersion in tin fluoride and boric acid solutions. The electrical conductivity of the coated plate was found to be nearly identical as that of a bare carbonaceous bipolar plate. The anticorrosion effect provided by the tin oxide coating was first investigated using a flat carbonaceous bipolar plate. $\mathrm{CO}_{2}$ release from the bare bipolar plate as a result of corrosion was significant above a holding potential of $1.3 \mathrm{~V}$, whereas $\mathrm{CO}_{2}$ release from the tin-oxide-coated specimen was not evident, even at potentials approaching 1.5 V. Moreover, further evidence of suppressed corrosion was also demonstrated by minimal changes in contact angles against a water droplet on the tin-oxide-coated surface before and after treatment.

Furthermore, the effectiveness of this anticorrosive coating was also investigated for a model bipolar plate having four gas flow channels; it was demonstrated that practically no $\mathrm{CO}_{2}$ release could be detected during the continuous test. FE-SEM observations confirmed that the tin oxide thin film remained intact on the plate surface including the channel inner wall, bottom, corners, and intersections. The results of this study demonstrate that tin-oxide-based surface coatings fabricated by the LPD method are effective anticorrosion materials for carbonaceous bipolar plates found in PEMFCs and, potentially, URFCs. 


\section{Acknowledgement}

This work was supported by Comprehensive Support Programs for Creation of

Regional Innovation, Science and Technology Incubation Program in Advanced Regions (FY2009), and "Research for Promoting Technological Seeds A (Discovery Type)" from the Independent Administrative Corporation, Japan Science and Technology Agency (JST), Japan.

\section{References}

[1] A. Hermann, T. Chaudhuri and P. Spagnol, Int. J. Hydrogen Energy, 30, 1297-1302 (2005).

[2] T. Kinumoto, K. Nagano, T. Tsumura and M. Toyoda, J. Power Sources, 195, 6473-6477 (2010)

[3] H.-Y. Jung, S.-Y. Huang, P. Ganesan and B. N. Popov, J. Power Sources, 194, 972-975 (2009).

[4] S.-H. Wang, J. Peng, W.-B. Lui and J.-S. Zhang, J. Power Sources, 162, 486-491 (2006).

[5] T. Fukutsuka, T. Yamaguchi, S.-I. Miyano, Y. Matsuo, Y. Sugie and Z. Ogumi, J. Power Sources, 174, 199-205 (2007).

[6] S. Karimi, N. Fraser, B. Roberts and F. R. Foulkes, Adv. Mater. Sci. Eng., Vol. 2012, Article ID 828070, 22 pages, (2012). 
[7] K. Miyazaki, M. Nose, T. Kinumoto, T. Abe, T. Fukutsuka and Z. Ogumi, Carbon, 50, 1644-1649 (2012).

[8] T. Kinumoto, N. Eguchi, M. Matsuoka, T. Tsumura and M. Toyoda, ECS Trans., 50, 1701-1706 (2012).

[9] H. Wang and J. A. Turner, J. Power Sources, 170, 387-394 (2007).

[10] H. Y. Y. Ko, M. Mizuhata, A. Kajinami and S. Deki, J. Mater. Chem., 12, 1495-1499 (2002).

[11] S. Deki, S. Iizuka, M. Mizuhata and A. Kajinami, J. Electroanal. Chem., 584, 38-43 (2005).

[12] O. Adrianowycz, Next Generation Bipolar Plates for Automotive PEM Fuel Cells, DOE Hydrogen Program Review, U.S. Department of Energy (2007).

[13] T. Kinumoto, K. Takai, Y. Iriyama, T. Abe, M. Inaba and Z. Ogumi, J. Electrochem. Soc., 153, A58-A63 (2006).

[14] H.-S. Choo, T. Kinumoto, S.-K. Jeong, Y. Iriyama, T. Abe, and Z. Ogumi, J. Electrochem. Soc., 154, B1017-B1023 (2007).

[15] M. Nose, T. Kinumoto, H-S. Choo, K. Miyazaki, T. Abe and Z. Ogumi, Chem. Lett., 38, 788-789 (2009). 
[16] M. Inaba, Chemical Degradation of Perfluorinated Sulfuric Acid Membranes, in: F.N. Büchi, M. Inaba and T. J. Schmidt (Eds.), Polymer Electrolyte Fuel Cell Durability, Springer, New York, pp. 57-69, (2008).

[17] S. H. Sun, G. W. Meng, G. X. Zhang, T. Gao, B. Y. Geng, L. D. Zhang and J. Zuo, Chem. Phys. Lett., 376, 103-107 (2003).

[18] K. Kinoshita, Carbon: Electrochemical and Physicochemical Properties, Wiley, New York, pp. 316-334 (1988).

[19] A. Masao, S. Noda, F. Takasaki, K. Ito and K. Sasaki, Electrochem. Solid-State Lett., 12, B119-B122 (2009).

[20] K. Kanda, S. Hayashi, F. Takasaki, Z-Y. Noda, S. Taniguchi, Y. Shiratori, A. Hayashi and K. Sasaki, ECS Trans., 41, 2325-2331 (2011).

[21] T. Kinumoto, K. Nagano, T. Tsumura and M. Toyoda, Electrochemistry, 79, 334-336 (2011).

[22] J. Pettersson, B. Ramsey and D. Harrison, J. Power Sources, 157, 28-34 (2006). 


\section{Figure captions}

Figure 1. (a) Photograph and (b) optical microscope image of the carbonaceous bipolar plate after immersion in $\mathrm{SnF}_{2}$ and boric acid solutions $\left(0.1 \mathrm{~mol} \mathrm{dm}^{-3}\right)$ for $30 \mathrm{~h}$.

Figure 2. FE-SEM images of (a) bare and (b) tin-oxide-coated areas of the carbonaceous bipolar plate surfaces.

Figure 3. Energy dispersive X-ray spectrum of the carbonaceous bipolar plate surface immersion area.

Figure 4. $\mathrm{CO}_{2}$ release from bare and tin-oxide-coated carbonaceous bipolar plates during the continuous test under $\mathrm{N}_{2}$ atmosphere at $80{ }^{\circ} \mathrm{C}$.

Figure 5. FE-SEM images of the (a) bare and (b) tin-oxide-coated bipolar plate surfaces after continuous tests.

Figure 6. Contact angles against a water droplet for bare (ם) and tin-oxide-coated carbonaceous plates against the holding potential after long-term tests. 
Figure 7. Photograph of the carbonaceous bipolar plate with four gas flow channels used for the model study.

Figure $8 . \mathrm{CO}_{2}$ release from the carbonaceous plate coated with tin oxide after the continuous test under $\mathrm{N}_{2}$ atmosphere.

Figure 9. FE-SEM images of the (a) bare and (b) tin-oxide-coated carbonaceous bipolar plates after continuous tests. 

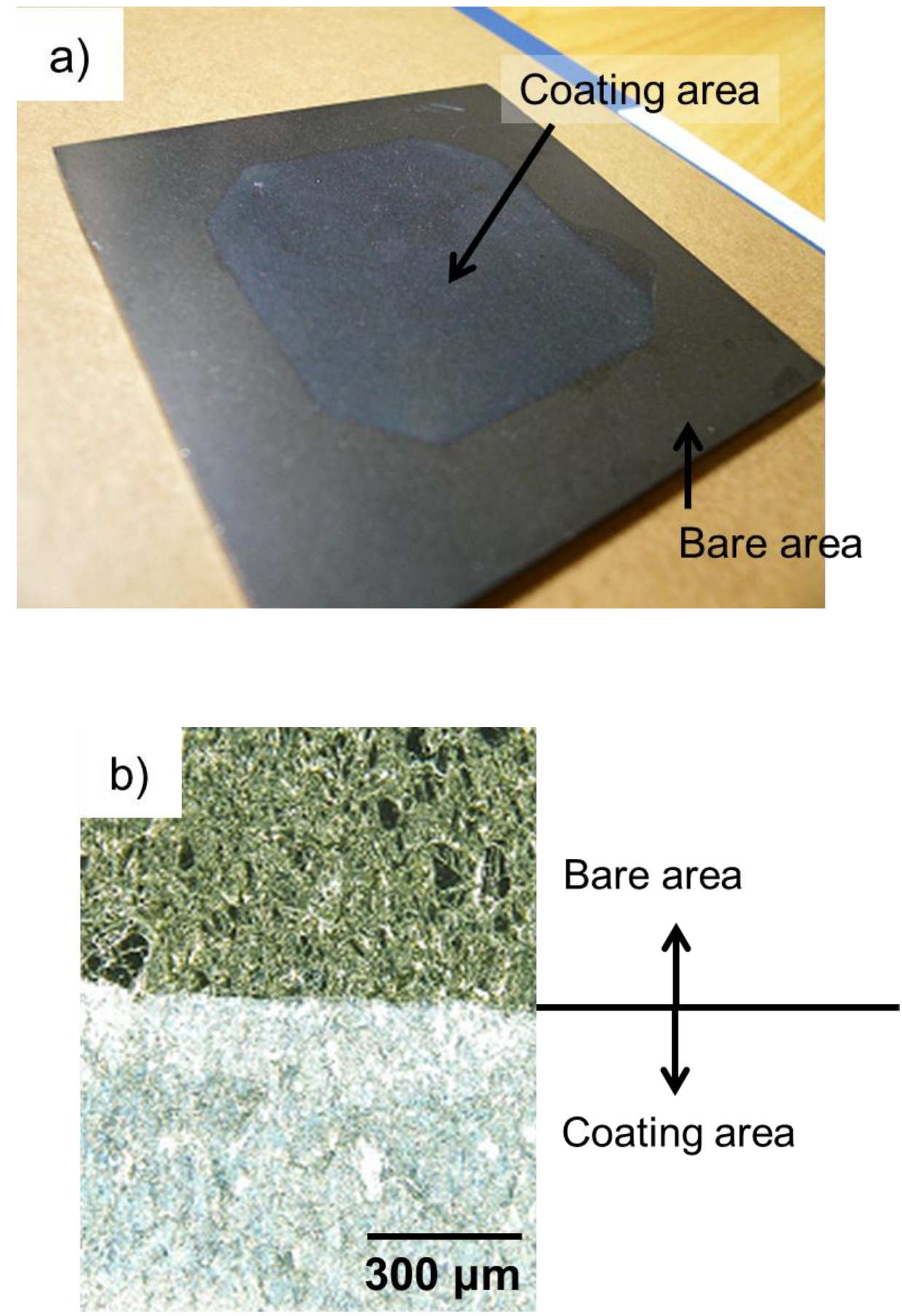

Figure 1. (a) Photograph and (b) optical microscope image of the carbonaceous bipolar plate after immersion in $\mathrm{SnF}_{2}$ and boric acid solutions $\left(0.1 \mathrm{~mol} \mathrm{dm}^{-3}\right)$ for $30 \mathrm{~h}$.

T. Kinumoto et al., Fig. 1 


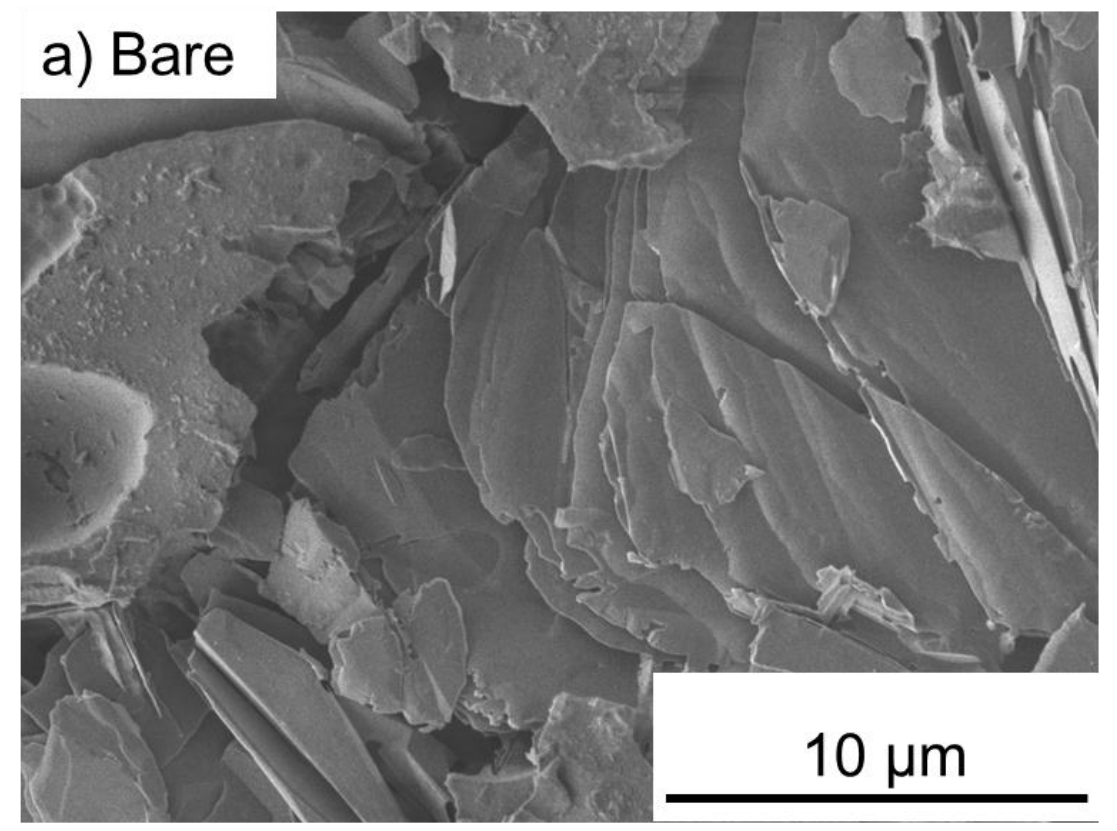

\section{b) Coated}

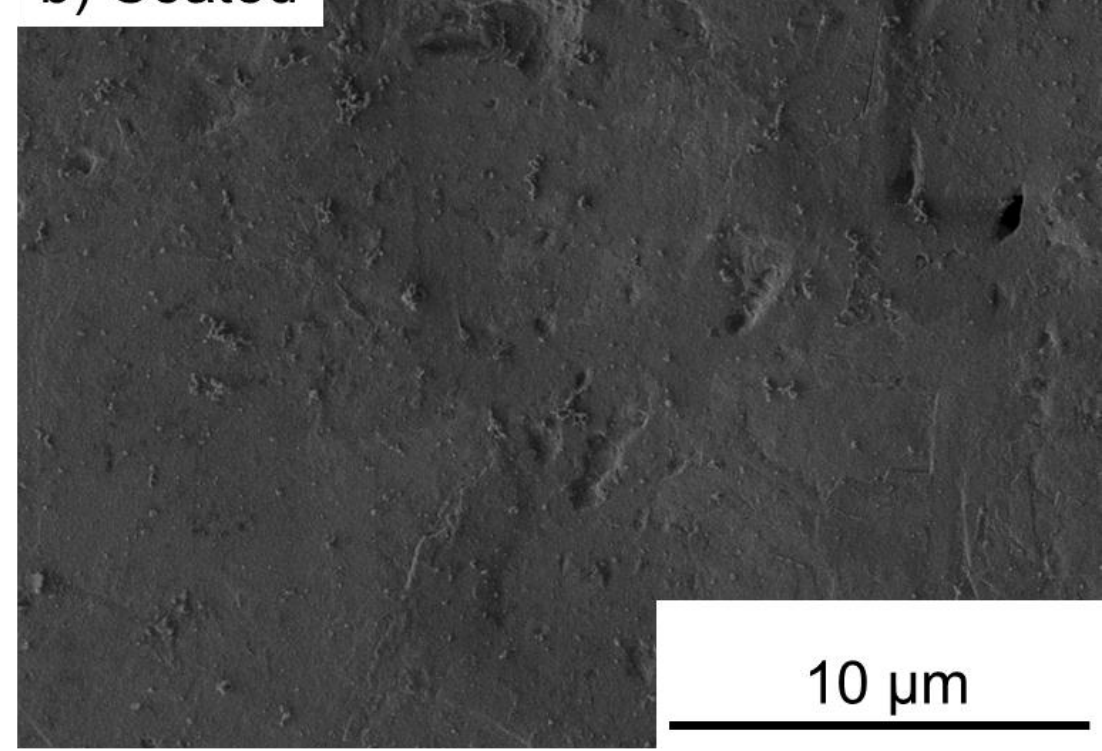

Figure 2. FE-SEM images of (a) bare and (b) tin-oxide-coated areas of the carbonaceous bipolar plate surfaces.

T. Kinumoto et al., Fig. 2 


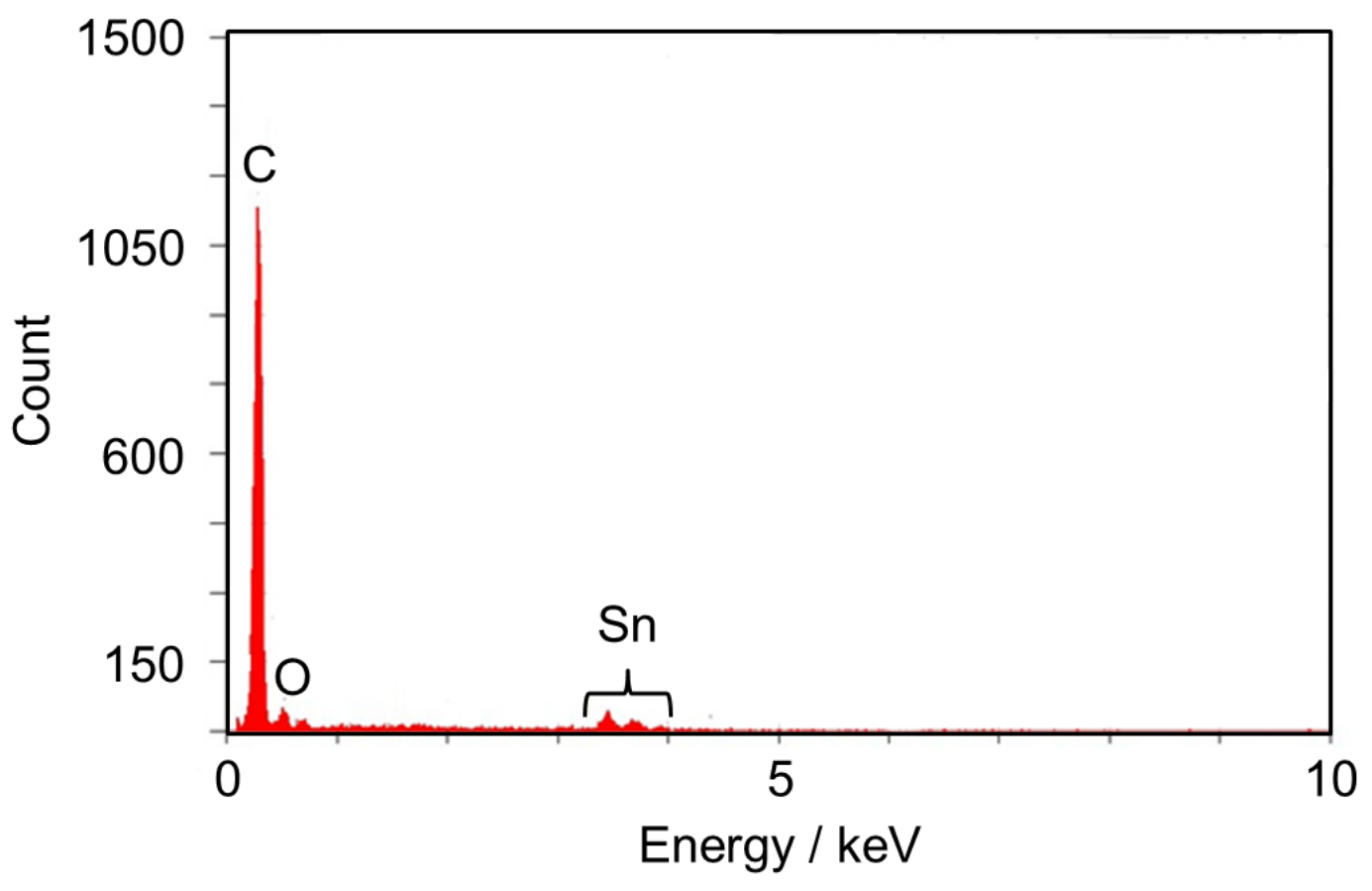

Figure 3. Energy dispersive X-ray spectrum of the carbonaceous bipolar plate surface immersion area.

T. Kinumoto et al., Fig. 3 


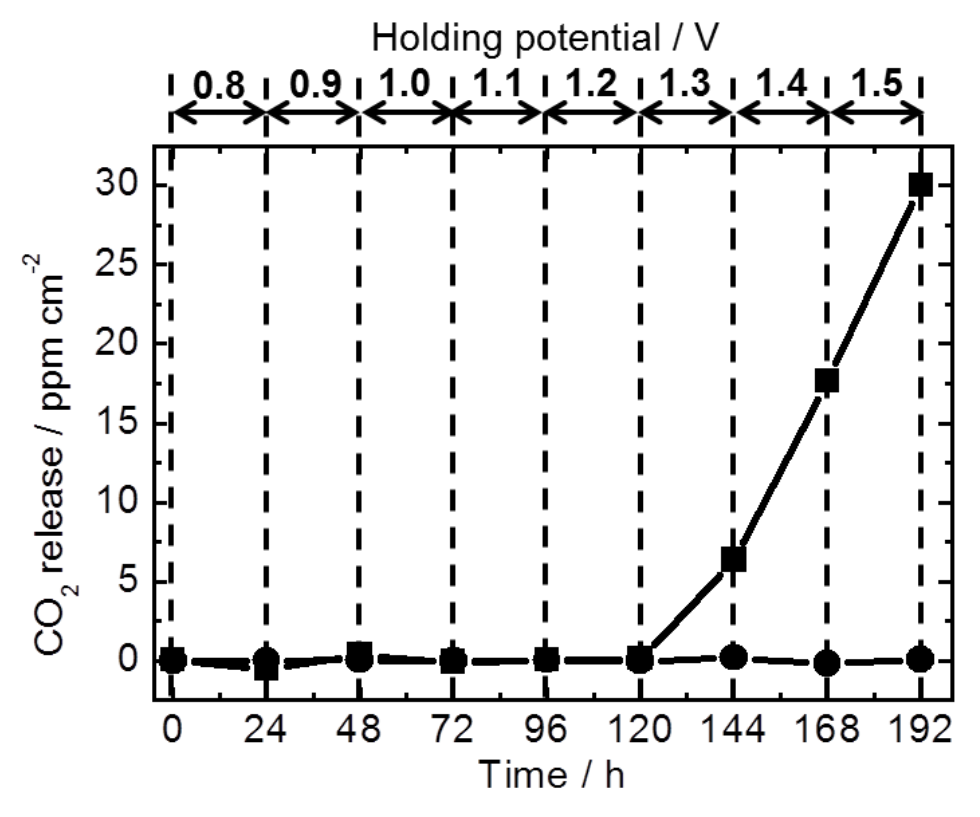

Figure 4. $\mathrm{CO}_{2}$ release from bare $(\boldsymbol{\square})$ and tin-oxide-coated $(\bullet)$ carbonaceous bipolar plates during the continuous test under $\mathrm{N}_{2}$ atmosphere at $80{ }^{\circ} \mathrm{C}$.

T. Kinumoto et al., Fig. 4 


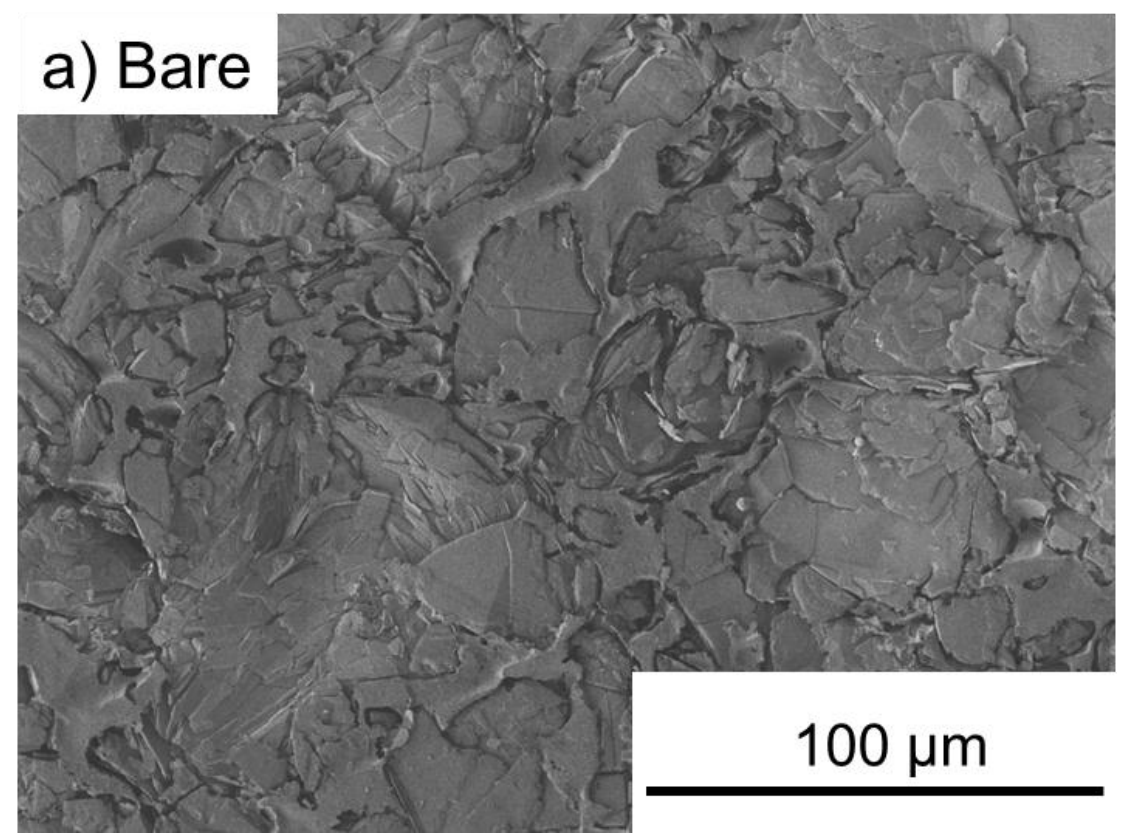

\section{b) Coated}

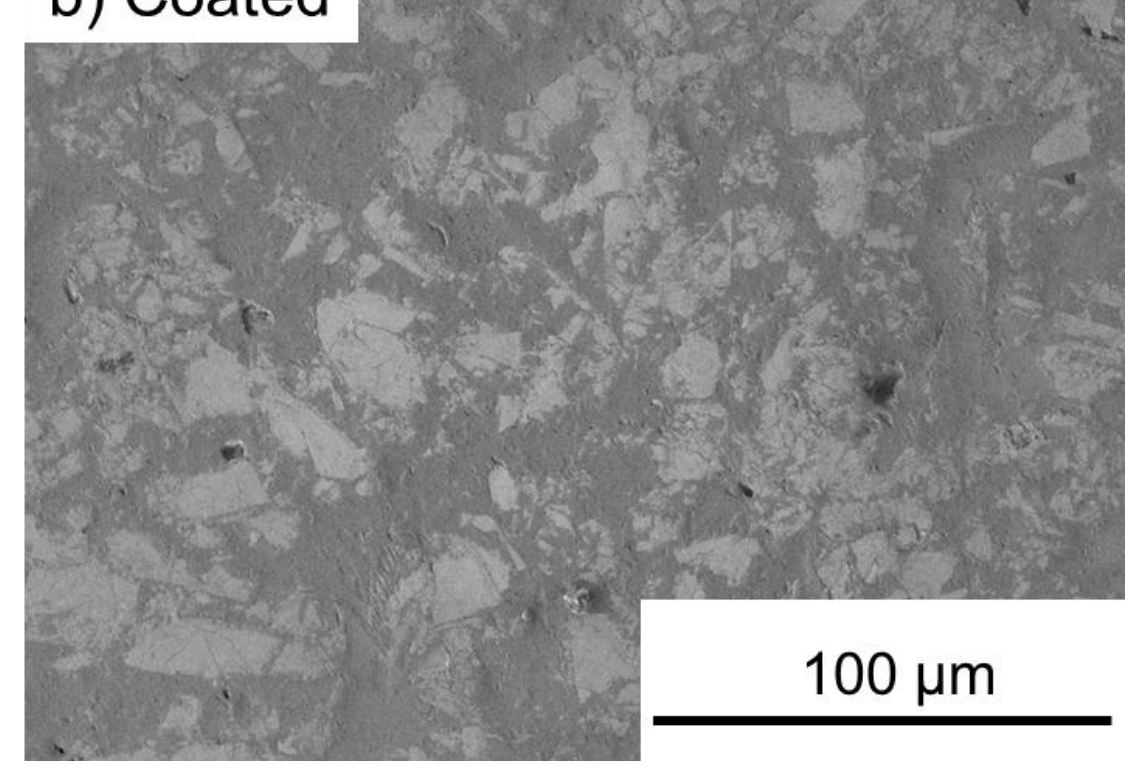

Figure 5. FE-SEM images of the (a) bare and (b) tin-oxide-coated bipolar plate surfaces after continuous tests.

T. Kinumoto et al., Fig. 5 


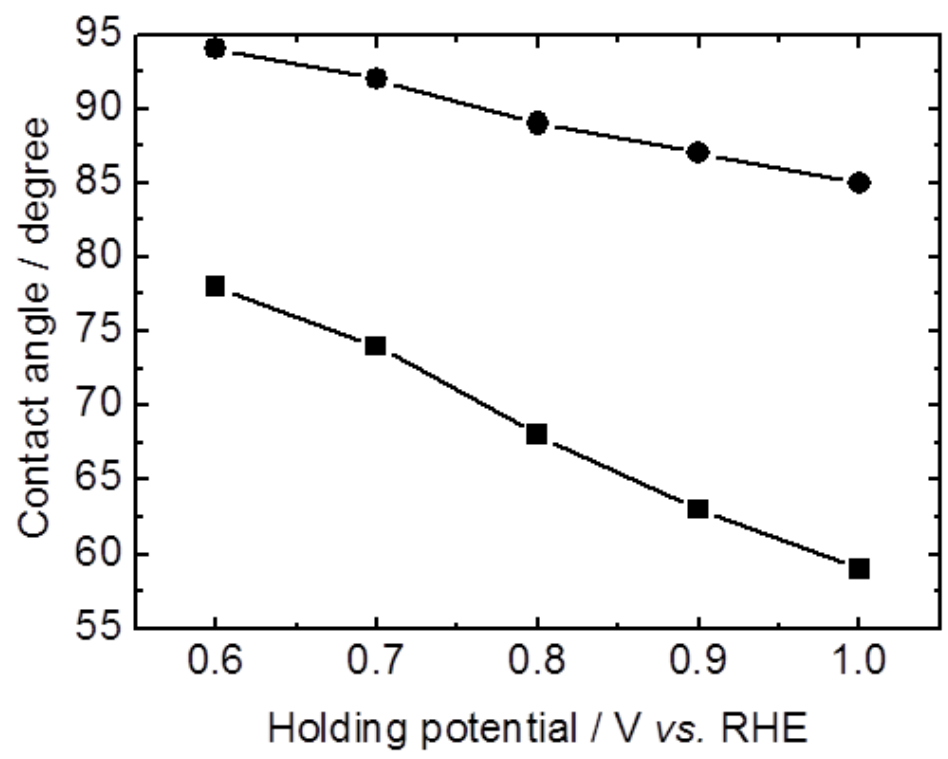

Figure 6. Contact angles against a water droplet for bare and tin-oxide-coated carbonaceous plates against the holding potential after long-term tests.

T. Kinumoto et al., Fig. 6 


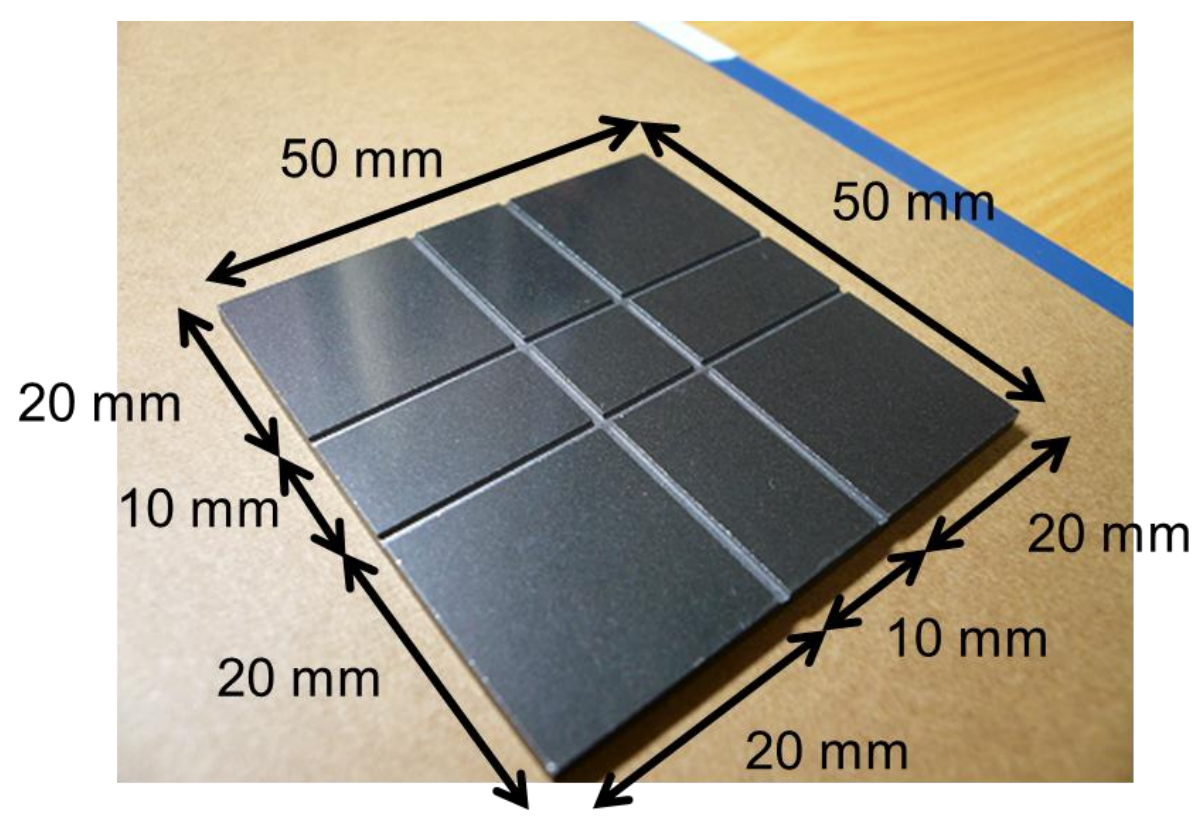

Figure 7. A photograph of the carbonaceous bipolar plate with four gas flow channels used for the model study.

T. Kinumoto et al., Fig. 7 


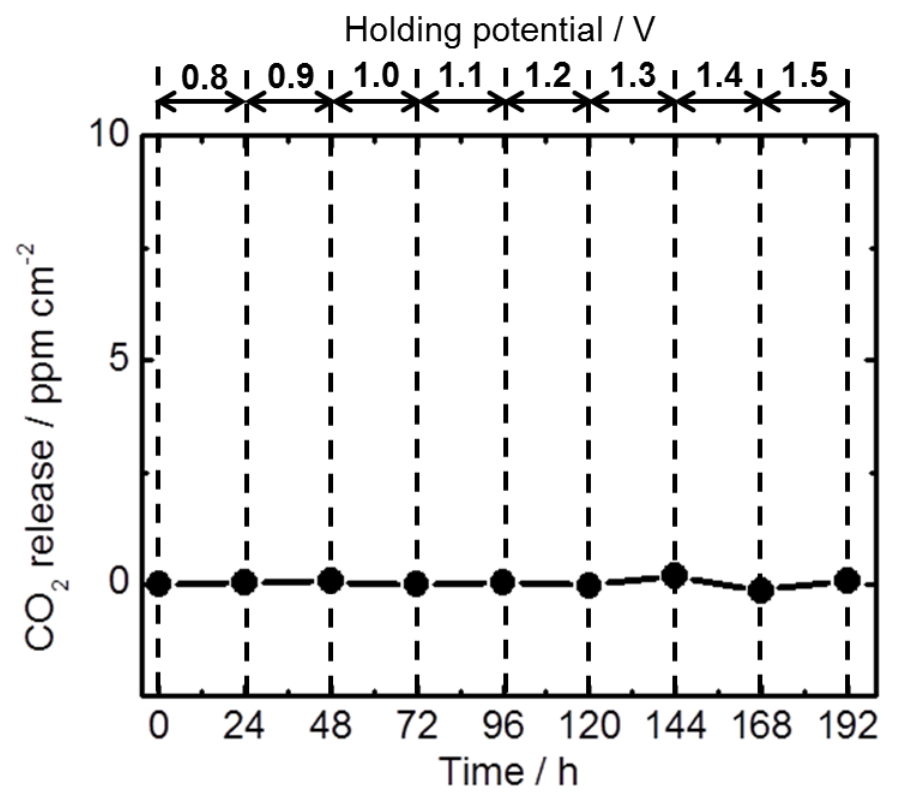

Figure $8 . \mathrm{CO}_{2}$ release from the carbonaceous plate coated with tin-oxide after the continuous test under $\mathrm{N}_{2}$ atmosphere.

T. Kinumoto et al., Fig. 8 

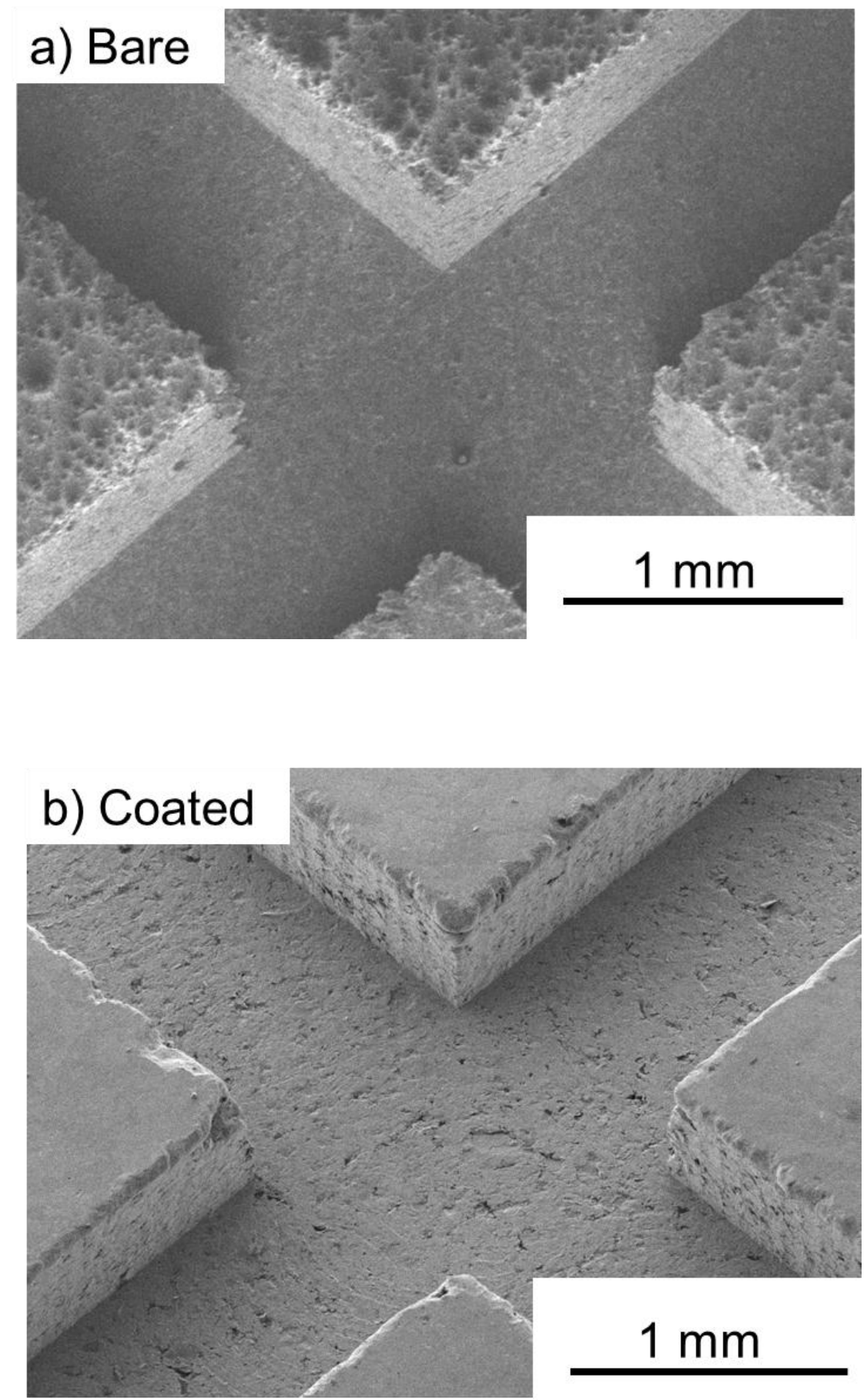

Figure 9. FE-SEM images of (a) bare and (b) tin-oxide-coated carbonaceous bipolar plates after continuous tests.

T. Kinumoto et al., Fig. 9 